\title{
Intelligent Seismic-Acoustic System for Identifying the Location of the Areas of an Expected Earthquake
}

\author{
Telman Aliev, Qambar Quluyev, Farhad Pashayev, Ulkar Sattarova, Narmin Rzayeva \\ Institute of Control Systems of the Azerbaijan National Academy of Sciences, Baku, Azerbaijan \\ Email: pasha.farhad@gmail.com
}

Received 15 February 2016; accepted 25 April 2016; published 28 April 2016

Copyright (C 2016 by authors and Scientific Research Publishing Inc.

This work is licensed under the Creative Commons Attribution International License (CC BY).

http://creativecommons.org/licenses/by/4.0/

(c) (i) Open Access

\begin{abstract}
A brief overview of the state-of-the-art in the field of earthquake study and forecasting is presented in this paper. We analyze the principles of the methods of determining the coordinates of earthquake focuses by means of ground seismic stations. We demonstrate that those methods cannot be used in the system for monitoring of the beginning of the earthquake preparation process (in the network of RNM ASP stations). As we know, the earthquake preparation process is accompanied by spreading noisy seismic-acoustic signals. Theoretically, the system for monitoring of the beginning of the earthquake preparation process is based on the technologies for seismic-acoustic signal processing-Robust Noise Monitoring (RNM). Noise characteristics determined by RNM technologies indicate the beginning of anomalous seismic processes (ASP) and, consequently, the possibility of ASP monitoring. Considering that the seismic-acoustic signal can be represented as the sum of the useful signal and noise, we present the technologies for determining noise characteristics. It is demonstrated in the paper that a change in the estimate of the cross-correlation function between the useful signal and the noise, noise variance and the value of noise correlation determine the beginning of ASP. One RNM ASP station determines the beginning of ASP within a radius of about $500 \mathrm{~km}$. Determining the location of an expected earthquake requires a network of RNM ASP stations. We analyze the results of noise technologybased monitoring of anomalous seismic processes performed from July 2010 to June 2015 on nine seismic-acoustic stations built at the head of $10 \mathrm{~m}, 200 \mathrm{~m}, 300 \mathrm{~m}$ and $1400-5000 \mathrm{~m}$ deep wells. Based on the results of the experimental data obtained in the period covering over three years, an intelligent system has been built, which allows for identifying the location of the zone of an earthquake, using the combinations of time of change in the estimate of the correlation function between the useful signal and the noise of the seismic-acoustic information received from different stations 10 - 20 hours before the earthquake. In the long term, the system can be used by seismologists as a tool for determining the location of the zone of an expected earthquake.
\end{abstract}




\section{Keywords}

\section{Seismic-Acoustic Signal, Robust Noise Technologies, RNM ASP Station, Seismic-Acoustic Monitoring Centre, Earthquake Forecasting}

\section{Introduction}

It is known that much research has been carried out on the causes and nature of earthquakes [1]. The possibility of receiving various types of seismic information from the deep strata of the earth also remains a popular research subject [2] [3]. Methods, such as noise analysis [4]-[9], continuous monitoring system designing [10] [11], earthquake damage assessment and damage minimization [12]-[14], wavelet transform and finite elements [15]-[17], are employed in analysing seismic signals received during earthquakes. In all of these research papers, the problems associated with earthquake prediction are the basic research trend [18]-[21]. Different models and technologies have been and are being developed [22]-[24]; numerous population-oriented early warning systems, models and technologies for the rapid response of rescue groups of relevant agencies have been developed and commissioned [25]-[29]. Regardless of the aforementioned research papers, earthquakes are not predicted in good time, which leads to massive disastrous consequences.

Papers [11] [30] [31] propose a seismic-acoustic system for monitoring the earthquake origin process. The system consists of a network of nine seismic-acoustic stations for the robust noise monitoring of anomalous seismic processes (RNM ASPs). The experiments that have been conducted on these stations since 2010.07.01 establish that a cross-correlation emerges between the useful signal and the noise of the seismic-acoustic information during the ASP origin.

The results of the operation of these stations have demonstrated that each of them separately performs reliable indication of ASP origin processes that precede earthquakes based on the variation of the cross-correlation function between the useful signal and the noise. However, it is impossible to determine the coordinates of an expected earthquake with sufficient accuracy by using these stations. The experimental research has demonstrated that it is possible, however, to create an intelligent system, which would allow locating the ASP area by means of these stations. We consider one possible way to create such a system in the following paragraphs.

\section{Problem Statement}

It is known that in seismically active regions, after a certain period $T_{0}$ of the normal seismic state and at the end of a certain period $T_{1}$, an earthquake usually occurs due to originating ASPs.

Despite the difference in duration of $T_{0}$ and $T_{1}$, the problem of monitoring the beginning of the ASP origin comes down to providing a reliable indicator of the beginning of period $T_{1}$.

This matter has been considered in detail in [9] [11] [31].

Research [11] sets the problem for creating a technology and a system allowing one to register the starting instant of the period $T_{1}$. However, the experimental research [9] [11] [31] demonstrated that the beginning of $T_{1}$ does not take place only during the ASP origin. For this reason, besides the registration of the beginning of the period $T_{1}$, the monitoring of the beginning of the ASP origin also requires an indication of the change in the estimate of the cross-correlation function $R_{X \varepsilon}(\mu)$ between the useful signal $X(i \Delta t)$ and the noise $\varepsilon(i \Delta t)$.

Thereby, the present paper sets up the problem of using the estimate $R_{X \varepsilon}(\mu)$ of the seismic-acoustic signal $g(i \Delta t)$ as an informative attribute for indicating the beginning of the ASP origin, which requires calculation of the estimate $R_{X \varepsilon}(\mu)$ during the monitoring process.

Furthermore, the practical application of a network of RNM ASP stations also requires developing a technology for determining the location of the earthquake area.

Therefore, the present paper poses the problem of developing an intelligent system for monitoring the ASP origin, identifying the location of the area of an expected earthquake.

\section{Technology for Determining the Informative Attributes of the Latent Period of ASP Origin}

Our research demonstrated that when ASP arises at the start of period $T_{1}$, estimates of the cross-correlation 
function $R_{X \varepsilon}(\mu=0)$ between the useful signal $X(i \Delta t)$ and noise $\varepsilon(i \Delta t)$, the noise variance $D_{\varepsilon}$ and the noise correlation $R_{X E \varepsilon}(\mu=0)$ change in the first place [9] [11] [31]. The reason is that in the beginning of period $T_{0}$, noise $\varepsilon(i \Delta t)$ forms due to the influence of the ASP. Therefore, in period $T_{1}$, correlation arises between the useful signal $X(i \Delta t)$ and noise $\varepsilon(i \Delta t)$ and the estimate $R_{X \varepsilon}(\mu)$ grows sharply. For this reason, the estimate $R_{X \varepsilon}(\mu)$ can be regarded as the main informative attribute, whose use is reasonable during the monitoring of the latent period of ASP origin.

Since 2010.07.01, both conventional technologies and robust noise technologies have been used to register the beginning of the latent period of ASP origin on RNM ASP stations. We were unable to register period $T_{1}$ with sufficient reliability and authenticity by using estimates of conventional correlation and spectral technologies. When robust noise technology was put into practice, the estimate of the cross-correlation function $R_{X \varepsilon}(\mu)$ would change abruptly in the beginning of period $T_{1}$. This turned out to be the crucial factor, which allows the monitoring of the beginning of ASP origin with sufficient reliability. With this in mind, the estimate $R_{X \varepsilon}(\mu)$ was taken as an informative attribute in solving the problem of monitoring the ASP origin during the building of the network of RNM ASP stations.

The expression for determining the estimates of the relay correlation function $R_{g g}^{*}(\mu=0)$ between the useful signal $X(i \Delta t)$ and the noise $\varepsilon(i \Delta t)$ is given in [11] in the following form:

$$
\begin{aligned}
R_{X \varepsilon}^{*}(\mu=0) \approx & \frac{1}{N} \sum_{i=1}^{N}[\operatorname{sgn} g(i \Delta t) g(i \Delta t)-2 \operatorname{sgn} g(i \Delta t) g((i+1) \Delta t) \\
& +\operatorname{sgn} g(i \Delta t) g((i+2) \Delta t)] .
\end{aligned}
$$

It has also been shown that, with the estimates $R_{X \varepsilon}^{*}(\mu=0), R_{g g}^{*}(\mu=1), R_{g g}(\mu=1)$ available and using the equality of the relationship between $R_{g g}^{*}(\mu=1)$ and $R_{g g}(\mu=1)$ and $R_{X \varepsilon}^{*}(\mu=0)$ and $R_{X \varepsilon}(\mu=0)$

$$
\frac{R_{g g}^{*}(\mu=1)}{R_{g g}(\mu=1)}=\frac{R_{X \varepsilon}^{*}(\mu=0)}{R_{X \varepsilon}(\mu=0)},
$$

and the estimate $R_{X \varepsilon}(\mu=0)$ can be determined by the formula:

$$
R_{X \varepsilon}(\mu=0)=\frac{R_{g g}(\mu=1) R_{X \varepsilon}^{*}(\mu=0)}{R_{g g}^{*}(\mu=1)}
$$

Our experiments demonstrated that to raise the reliability and authenticity of the monitoring results, it is reasonable to also use the estimates of the noise correlation value $R_{X \varepsilon \varepsilon}(\mu=0)$ and the noise variance $D_{\varepsilon}$, which are determined by the following expressions [9] [11] [31] as additional informative attributes:

$$
\begin{gathered}
R_{X \varepsilon \varepsilon}(\mu)=R_{X \varepsilon}(\mu)+D_{\varepsilon}=\frac{1}{N} \sum_{i=1}^{N}\left[g^{2}(i \Delta t)+g(i \Delta t) g((i+2) \Delta t)-2 g(i \Delta t) g((i+1) \Delta t)\right] \\
D_{\varepsilon}=R_{X \varepsilon \varepsilon}(\mu=0)-R_{X \varepsilon}(\mu=0)
\end{gathered}
$$

Thus, it is possible to use formulas (1), (3), (4) and (5) to determine the estimates $R_{X \varepsilon}^{*}(\mu=0), R_{X \varepsilon}(\mu=0)$, $R_{X \varepsilon \varepsilon}(\mu=0)$, and $D_{\varepsilon}$, by means of which the monitoring of the ASP can be undertaken with sufficient reliability.

\section{Intelligent Technology and Systems for Identifying the Location of the Area of ASP Origin}

It is known that when an ASP enters its critical state, an earthquake occurs. Boundaries of the earthquake's focus and magnitude depend on the structure and nature of the strain-stress distribution in the rocks in the particular place. Rock deformation is uneven and transmits elastic waves. The volume of deformed rocks is an important factor determining the strength of the seismic impact and the formation of seismic-acoustic noise $g(i \Delta t)$. Each main burst is preceded by quite a long period of time $T_{1}$ of earthquake preparation. This period can last up to several dozens of hours.

The analysis of seismic information, received by means of acoustic sensors installed at the heads of suspended oil wells, has demonstrated that when ASPs arise, seismic-acoustic noise spreads in the deep strata of the Earth 
for several dozens of hours $T_{1}$ before the expected earthquake [9] [11] [31]. It has been experimentally established that monitoring the beginning of time $T_{1}$ by means of the technology described above is carried out quite reliably by RNM ASP stations (Figure 1). In the following paragraphs, we discuss the possibility of developing intelligent technology to identify the location of the ASP area by means of the information received from the stations built in nine seismically active Caspian regions (Figure 1). Those stations have the following geographical coordinates and their wells have the following depths:

\begin{tabular}{cccccc}
\hline Qum Island: & $40.310425^{\circ}$ & $50.008392^{\circ}$ & $3500 \mathrm{~m}$ & July & 2010 \\
Siazan: & $41.046217^{\circ}$ & $49.172058^{\circ}$ & $3145 \mathrm{~m}$ & November & 2011 \\
Naftalan: & $40.609521^{\circ}$ & $46.791458^{\circ}$ & $4000 \mathrm{~m}$ & May & 2012 \\
Shirvan: & $39.933170^{\circ}$ & $48.920745^{\circ}$ & $4900 \mathrm{~m}$ & November & 2011 \\
Neftchala: & $39.358333^{\circ}$ & $49.246667^{\circ}$ & $1430 \mathrm{~m}$ & June & 2012 \\
Nakhchivan: & $39.718000^{\circ}$ & $44.876000^{\circ}$ & $1800 \mathrm{~m}$ & March & 2013 \\
Qazakh & $41.311889^{\circ}$ & $45.108611^{\circ}$ & $200 \mathrm{~m}$ & August & 2013 \\
Turkmenistan & $38.530089^{\circ}$ & $56.654472^{\circ}$ & $300 \mathrm{~m}$ & August & 2013 \\
Cybernetic & $40.223252^{\circ}$ & $49.800833^{\circ}$ & $10 \mathrm{~m}$ & February & 2014 \\
\hline
\end{tabular}

The experiments carried out on the RNM ASP stations have demonstrated that the seismic-acoustic noises received by hydrophones from the deep strata of the Earth are direct precursors of the earthquake preparation process.

The results of the measuring and analysis of those noises were sent from each station to the server of the seismic-acoustic monitoring centre (MC) via the satellite communication. The system is also capable of transferring received data to servers of other MCs in the neighbouring countries of seismic-acoustic regions.

To carry out large-scale experiments on ASP monitoring, as Figure 1 shows, since 2010.07.01 RNM ASP stations have been made operational, one by one, at Qum Island, in Shirvan, Siazan, Naftalan, Neftchala, Nakhchivan (on the borders with Turkey and Iran), Turkmen01 (Turkmenistan), Qazakh (on the border with Georgia), and Cybernetic (Baku). The last three stations have been built on 300-m, 200-m and 10-m deep water wells, respectively. The stations were built on the wells, in which pipes are naturally filled with water. Hydrophones were placed inside at the depth of 10 - $20 \mathrm{~m}$ from the water level. The analysis of seismic-acoustic signals received by these stations has demonstrated that seismic-acoustic noises emerge during ASP origin. Those noises spread within a radius of 300 - $500 \mathrm{~km}$ dozens of hours before the seismic waves are registered by ground seismic stations.

Synchronous robust analysis of seismic-acoustic signals received from all stations via satellite communication is undertaken in the process of the network operation. Estimates of the noise characteristics $R_{X \varepsilon}(\mu)$, $R_{X \varepsilon \varepsilon}(\mu), D_{\varepsilon}$ are transmitted to the server of the MC from the stations. The changes in them are used to indicate, for instance, the beginning of the ASP origin $T_{1 i}$ and $T_{1 j}$ for the $i$-th and $j$-th stations.

The operating experience of the stations demonstrates that each of them separately allows for reliable

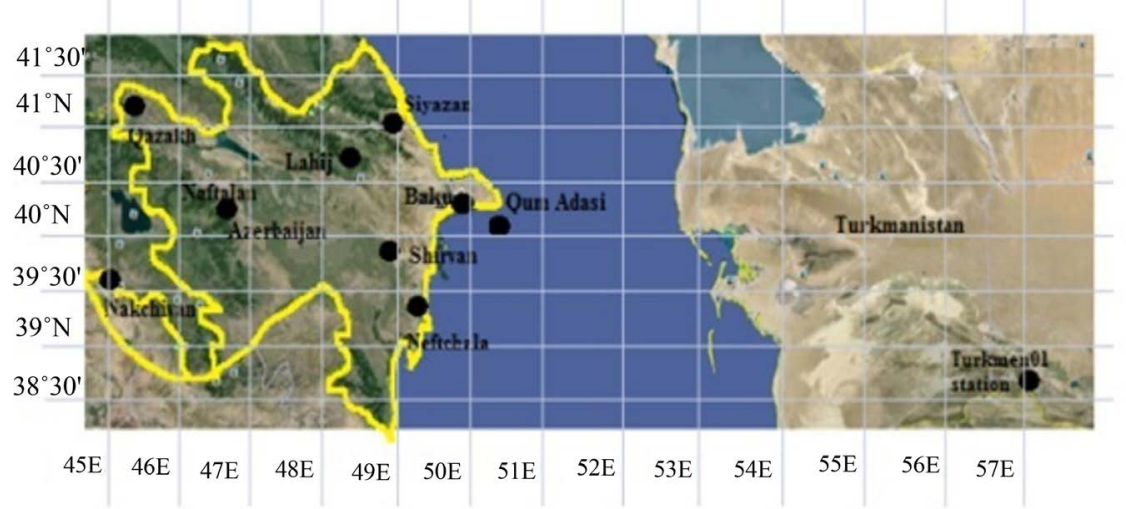

Figure 1. Map of the locations of RNM ASP stations in the Caspian seismically active region. 
indication of the process of origin of ASP, which precedes an earthquake. It also demonstrates that the results obtained by means of the network of those stations opens the way to developing an intelligent technology for identifying the location of the area of an expected earthquake. To do that, we first determine the combinations of moments of indication $T_{1 i}$ and $T_{1 j}$ by means of the network of these stations. Those combinations and the coordinates of their location are source data to solve the problem of identifying the location of ASP origin. To raise the level of authenticity and reliability of the obtained results, it is reasonable to use time differences $T_{1 i}-T_{1 j}$ for each selected pair of stations, alongside the combination of time of indication. In other words, solving the problem at hand requires determining not only the combination $T_{1 i}, T_{1 j}$ but also the time of indication of ASP between the stations, i.e. the difference $\Delta \tau_{i j}=\left(T_{1 i}-T_{1 j}\right)$, as source data.

Our experiments have demonstrated that it is difficult to determine the beginning of the time of indication $T_{1 i}$ with sufficient accuracy using the values of the estimates of noise characteristics. Thus, considering the importance and necessity of enhancing the accuracy, the proposed system provides for duplication of the process of determining $\Delta \tau_{i j}$. It was also found to be reasonable to use the extreme value of the estimate of the cross-correlation function $R_{g_{i} g_{j}}\left(\mu_{\max }\right)$ between the signals $g_{i}(i \Delta t)$ and $g_{j}(i \Delta t)$ obtained through different combinations of the RNM ASP stations to determine the time difference $\Delta \tau_{i j}=\left(T_{1 i}-T_{1 j}\right)$ by the following expressions:

$$
\begin{gathered}
R_{g_{i} g_{j}}\left(\mu_{\max }\right)=\frac{1}{N} \sum_{i=1}^{N} g_{i}(i \Delta t) g_{j}(i+\mu) \Delta t \\
R_{g_{i} g_{j}}^{*}\left(\mu_{\max }\right)=\frac{1}{N} \sum_{i=1}^{N} g_{i}^{2}(i \Delta t) g_{j}^{2}(i+\mu) \Delta t \\
R_{g_{i} g_{j}}^{*}\left(\mu_{\max }\right)=\frac{1}{N} \sum_{i=1}^{N} g_{i}(i \Delta t) g_{j}^{2}(i \Delta t)
\end{gathered}
$$

In that case, the procedure for determining the difference in the time of monitoring between different stations on the MC server comes down to the following:

Determining when the beginning of period $T_{1 i}$ of the ASP origin is registered by the first station Qum Island;

Determining the time of monitoring for the second (Shirvan), third (Siazan), fourth (Naftalan), etc. stations;

Determining the sets of estimates of cross-correlation functions $R_{g_{v} g_{j}}(i \Delta t), R_{g_{v} g_{j}}^{*}(i \Delta t)$ by the Expressions (6)-(8) and further, selecting from the obtained estimates those time shifts $\mu \cdot \Delta t$, at which the curve of the cross-correlation function has the peak value, i.e. the extreme value; these time shifts are used to determine $\Delta \tau_{i j}=\left(T_{1 i}-T_{1 j}\right)$, i.e. the time difference in registration of ASP by the $i$-th and $j$-th stations, respectively; using the found time differences $\Delta \tau_{1 i}=\left(T_{1 i}-T_{1 j}\right)$ as source data to identify the location of the ASP area.

Thus, in the proposed system (Figure 2), the estimates of the noise characteristics $R_{X \varepsilon}(\mu), R_{X \varepsilon \varepsilon}(\mu)$ and $D_{\varepsilon}$ obtained as a result of ASP monitoring performed by the Qum Island, Shirvan, Siazan, Naftalan, Neftchala, Nakhchivan, Turkmen01 (Turkmenistan), Qazakh and Cybernetic (Baku) RNM ASP stations are synchronously transmitted via satellite communication to the MC server. The obtained results are used to form the combination of sequences of indication times $T_{1 i} T_{1 j}$ and the combinations of time differences $\Delta \tau_{i j}$, which are used as source data to identify the location of an expected earthquake.

The experiments on the said stations carried out in the period from 2010.07.01 to 2014.06.01 have demonstrated the following active earthquake areas in Azerbaijan and neighbouring regions within a radius of 500 $600 \mathrm{~km}$ around the network of the RNM ASP stations.

Turkmen coast of the Caspian Sea;

In the Caspian Sea south of the Absheron peninsula;

In the Caspian Sea north of the Absheron peninsula;

In the Shirvan region of Azerbaijan;

In the north-western regions of Azerbaijan;

In the southern regions of Azerbaijan;

South of the Caucasus region of the Russian Federation;

In the north-eastern regions of Iran;

In the north-western regions of Iran (near Tabriz);

On the Iranian-Iraqi-Turkish border; 


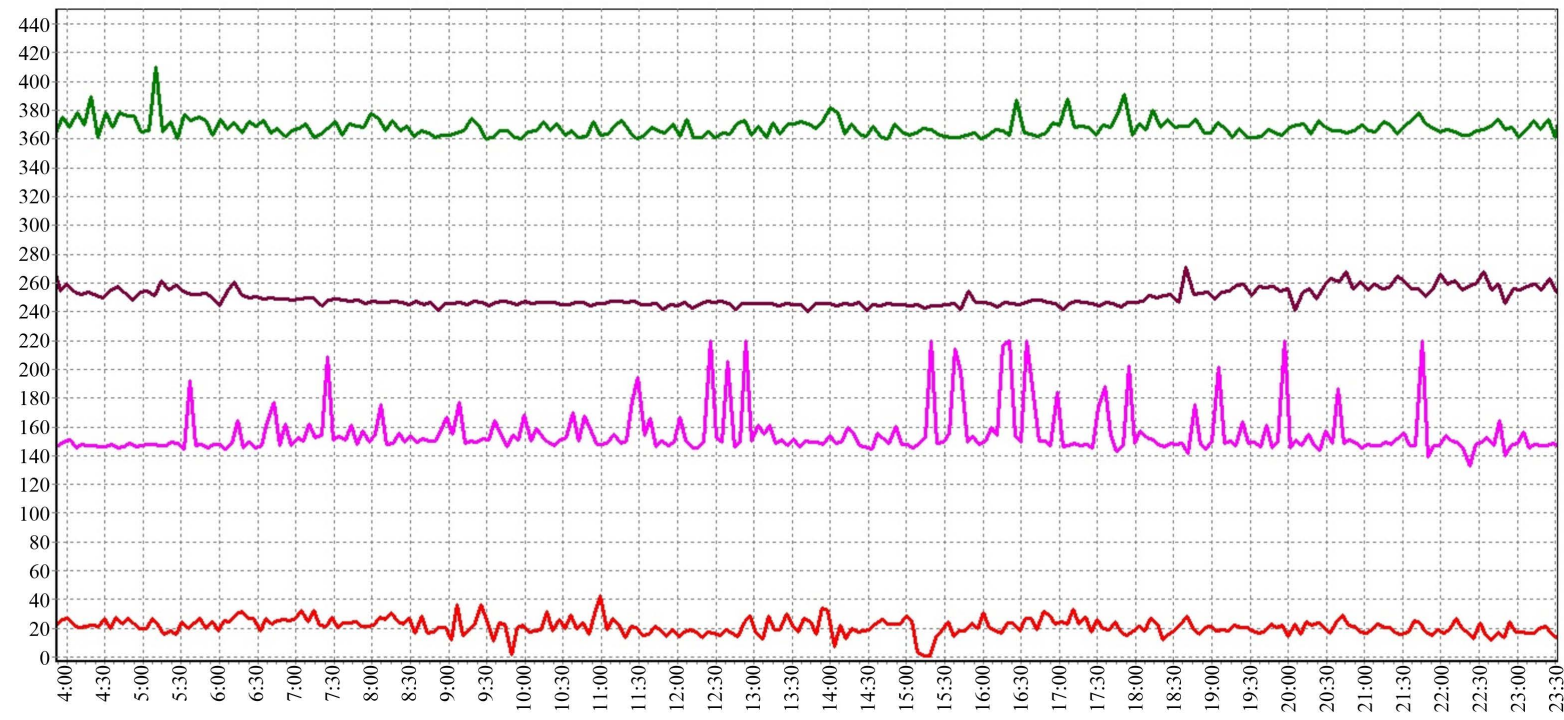

Figure 2. VII—Siazan, Qum Island, Shirvan, Neftchala 2013-03-26 Georgia-Russia.

In the northern regions of Iran;

In the eastern regions of Turkey;

In the western regions of Georgia (Black Sea).

Some of the results of the registration of ASP in those areas by the RNM ASP stations are given in [11].

Numerous earthquakes with magnitudes of 3 - 4 have occurred in those regions in the last 1.5 - 2 years. For each area, the combinations of the sequence of the times of the ASP registration by Qum Island, Shirvan, Siazan, Neftchala, Naftalan and Nakhchivan by the RNM ASP stations practically repeated themselves. Our analysis of the recorded charts has demonstrated that each sequence combination of the time of the indication of the current ASP corresponds to one of the concrete earthquake areas. After studying the problem of interpretation of the experimental materials for over 2 years, we have learned to identify the location of the area of an expected earthquake, error-free intuitively, using these combinations of time. It then became obvious that the problem of identifying the location of an expected earthquake can be solved by using expert systems (ESs). This, in its turn, demonstrated the possibility of creating an ES which will allow seismologists to use the network of the RNM ASP stations as a tool to determine the area of an expected earthquake.

The experimental version of the ES for identifying the location of the ASP area (ESILA) proposed in this paper is based on the knowledge base (KB) comprising the totality of the sets $W_{1}, W_{2}, W_{3}, \cdots, W_{13}$ of the locations of the respective areas. The elements of each of these sets are formed from the data of the charts recording the parameters of all earthquakes registered by the RNM ASP stations in all 13 areas from 2010.07.01 to the present day. Each element of the KB consists of the combination of the sequence of times of the ASP indication by the stations $T_{1 i}, T_{1 j}$, the combination of the differences in times of the indication $\Delta \tau_{i j}$, and from the combination of the estimates of the cross-correlation function $R_{X \varepsilon}(\mu=0)$. Each element of the KB also contains the value of magnitude $M_{i}$ determined during the corresponding earthquakes by ground seismic stations. The date of the earthquake is also specified in each element. In the case when there is only one element, the KB appears as follows:

$$
\begin{gathered}
W_{1}\left\{\begin{array}{ccccc}
T_{11}^{1(1)} & T_{11}^{2(1)} & \cdots & T_{11}^{6(1)} & M_{1} \\
\Delta \tau_{11}^{1} & \Delta \tau_{21}^{1} & \ddots & \Delta \tau_{61}^{1} & M_{1} \\
R_{X \varepsilon}^{1(1)}(\mu=0) & R_{X \varepsilon}^{2(1)}(\mu=0) & \cdots & R_{X \varepsilon}^{6(1)}(\mu=0) & M_{1}
\end{array}\right\} \\
W_{2}\left\{\begin{array}{ccccc}
T_{11}^{1(2)} & T_{11}^{2(2)} & \cdots & T_{11}^{6(2)} & M_{2} \\
\Delta \tau_{11}^{2} & \Delta \tau_{21}^{2} & \ddots & \Delta \tau_{61}^{2} & M_{2} \\
R_{X \varepsilon}^{1(2)}(\mu=0) & R_{X \varepsilon}^{2(2)}(\mu=0) & \cdots & R_{X \varepsilon}^{6(2)}(\mu=0) & M_{2}
\end{array}\right\}
\end{gathered}
$$




$$
W_{13}\left\{\begin{array}{ccccc}
T_{11}^{1(13)} & T_{11}^{2(13)} & \cdots & T_{11}^{6(13)} & M_{13} \\
\Delta \tau_{11}^{13} & \Delta \tau_{21}^{13} & \ddots & \Delta \tau_{61}^{13} & M_{13} \\
R_{X \varepsilon}^{1(13)}(\mu=0) & R_{X \varepsilon}^{2(13)}(\mu=0) & \cdots & R_{X \varepsilon}^{6(13)}(\mu=0) & M_{13}
\end{array}\right\}
$$

Each set $W_{1}-W_{13}$ of the experimental version of the KB consists of several dozens of such elements and new elements are added during each new earthquake. During the operation of the ES, after the monitoring and indication of the time of the beginning of the current ASP has been completed, the stations form the current combinations of the sequence of times of indication $T_{1 i}, T_{1 j}$, the combinations of differences in times of indication $\Delta \tau_{i j}$, and the combinations of the values of estimates $R_{X \varepsilon}(\mu)$.

On 2014.01.05, the experimental phase of the identification of the location of earthquake areas by ESILA was launched. This phase is carried out as follows. The current element is formed based on the results of monitoring of the network of RNM ASP stations. After that, the current element is compared with all elements of the sets $W_{1}, W_{2}, W_{3}, \cdots, W_{13}$ in the identification unit of the expert system (IUES). If it matches any element of any set, the location of the area of an expected earthquake is identified based on the number of the current element. The number of the ASP area is saved in the decision-making unit (DMU) of the ES. At the same time, the current element is entered into the set of the KB. Thus, new elements are continuously written into the KB during the ESILA operation and the network of RNM ASP stations and ESILA operate as a single system.

To check the authenticity and reliability of the identification of the location of the ASP area, the described ESILA was tested during all subsequent earthquakes. The obtained results have demonstrated the real possibility of practical application of the experimental version of ESILA to identify the location of the ASP area, which creates prerequisites for using the system in question as a tool in determining the location of the area of an expected earthquake. Taking this prospect into account, a function of forming the following information and providing it to seismologists was included in the list of basic functions of the DMU of ESILA: date of the current ASP and the number of the area of the expected earthquake; results of the current monitoring performed by the RNM ASP stations; estimated lead time at the beginning of ASP monitoring compared with the time of registration of the expected earthquake by ground seismic stations; list of all elements previously registered in the corresponding set during the origin of the previous ASP in the estimated location of the area of the expected earthquake (with dates); the amount of elements matching the current elements; magnitudes of previous earthquakes; minimum magnitude of the expected earthquake; if the KB contains no elements matching at least some of the elements in the sets $W_{1} \div W_{13}$, information on the impossibility of identifying the earthquake area is formed in the DMU.

Analysing the experience of the use of the ES in identifying the location of the area of the expected earthquake has demonstrated that improved reliability and authenticity of the obtained results requires increasing the number of RNM ASP stations. Taking this into account, since the beginning of 2013, a station in the Nakhchivan Autonomous Republic near the border with Turkey and Iran and Turkmen01station in Turkmenistan have been commissioned. On 2013.07.01, another station was built in the Qazakh region on the border with Georgia and at the Institute of Cybernetics (Baku) (Figure 1).

It should be noted that the results of the experimental monitoring of the station built in the basement of the Institute of Cybernetics in a 10-m deep well practically match the readings of the Qum Island station built in a 3500-m deep well.

\section{Results Obtained by the Intelligent System Identifying Areas of Expected Earthquakes from 2013.01.01 to 2014.07.02}

As was mentioned earlier, the test operation of the system under discussion started on 2014.01.06. In this period, some identification errors were detected during weaker earthquakes. Besides, we also detected erroneous identification results at 2 or 3 RNM ASP stations simultaneously during a malfunction of the power supply system, communication systems and hydrophone, controller and other units. In the normal state of operation of all RNM ASP stations, no errors were detected in the results of the identification of the location of areas of expected earthquakes with strength exceeding 5 points.

The list of the location of areas of expected earthquakes identified from the archived monitoring results in 2013-2014 is very long, which is why Table 1 contains only the results of 10 identified areas of expected earthquakes with magnitude over 5 points from 2013.01.01 to 2014.07.06. Figures 2-11 are the recorded ASP charts 
Table 1. Identified areas of expected earthquakes.

(a)

\begin{tabular}{|c|c|c|c|c|c|c|c|c|c|c|}
\hline № & $\begin{array}{c}\text { Date, time, } \\
\text { coordinates, magnitudes } \\
\text { and depth of earthquake } \\
\text { epicentre }\end{array}$ & $\Delta \tau_{12}$ & $\Delta \tau_{13}$ & $\Delta \tau_{14}$ & $\Delta \tau_{15}$ & $\Delta \tau_{16}$ & $\Delta \tau_{17}$ & $\Delta \tau_{18}$ & $\Delta \tau_{19}$ & $\Delta \tau_{1 x_{\varepsilon}}$ \\
\hline 1 & 2 & 4 & 5 & 6 & 7 & 8 & 9 & 10 & 11 & 12 \\
\hline 1 & $\begin{array}{l}\text { 2013-03-26 } \\
\text { 23:35:25.0 UTC } \\
\text { 43.19N; } 41.67 \mathrm{E} \\
\text { mag 4.8; } 10 \mathrm{~km}\end{array}$ & 35 & -120 & - & 135 & $*$ & - & * & - & 300 \\
\hline 2 & $\begin{array}{c}\text { 2013-05-28 } \\
00: 09: 52.0 \mathrm{UTC} \\
\text { 43.22N; 41.58E } \\
\text { mag 5.2; } 2 \mathrm{~km}\end{array}$ & -115 & -150 & -250 & - & * & - & * & - & 150 \\
\hline 3 & $\begin{array}{c}\text { 2013-09-17 } \\
\text { 04:09:13.0 UTC } \\
\text { 42.13N; 45.80E } \\
\text { mag 5.1; } 2 \mathrm{~km}\end{array}$ & - & -150 & - & 390 & * & 120 & * & - & 100 \\
\hline 4 & $\begin{array}{c}\text { 2013-11-24 } \\
\text { 18:05:41.0 UTC } \\
34.06 \mathrm{~N} ; 45.52 \mathrm{E} \\
\text { mag 5.6; } 10 \mathrm{~km}\end{array}$ & - & * & - & -10 & -60 & * & * & - & 160 \\
\hline 5 & $\begin{array}{l}\text { 2014-01-10 } \\
00: 45: 31.0 \mathrm{UTC} \\
41.86 \mathrm{~N} ; 49.41 \mathrm{E} \\
\text { mag 4.8; } 80 \mathrm{~km}\end{array}$ & - & 20 & - & 110 & * & - & -10 & - & 110 \\
\hline 6 & $\begin{array}{c}\text { 2014-01-14 } \\
\text { 13:55:02.0 UTC } \\
40.33 \mathrm{~N} ; 52.95 \mathrm{E} \\
\text { mag 5.2; } 48 \mathrm{~km}\end{array}$ & - & -45 & * & -120 & * & * & - & - & 160 \\
\hline 7 & $\begin{array}{c}\text { 2014-01-28 } \\
\text { 23:47:35.0 UTC } \\
32.45 \mathrm{~N} ; 50.02 \mathrm{E} \\
\text { mag 4.9; } 10 \mathrm{~km}\end{array}$ & -135 & - & - & 100 & -300 & - & - & - & 120 \\
\hline 8 & $\begin{array}{l}\text { 2014-02-10 } \\
\text { 12:06:48.0 UTC } \\
\text { 40.23N; } 48.63 \mathrm{E} \\
\text { mag 5.4; } 55 \mathrm{~km}\end{array}$ & -300 & - & - & - & 45 & 75 & - & - & 75 \\
\hline 9 & $\begin{array}{l}\text { 2014-06-07 } \\
\text { 06:05:32.4 UTC } \\
\text { 40.32N; } 51.58 \mathrm{E} \\
\text { mag 5.4; } 44 \mathrm{~km}\end{array}$ & 145 & 20 & - & -70 & - & - & - & 120 & 80 \\
\hline 10 & $\begin{array}{c}\text { 2014-06-29 } \\
\text { 17:26:10.4 UTC } \\
41.62 \mathrm{~N} ; 46.68 \mathrm{E} \\
\text { mag 5.1; } 20 \mathrm{~km}\end{array}$ & 305 & -85 & - & - & - & 315 & * & - & 100 \\
\hline
\end{tabular}


(b)

\begin{tabular}{cccccccccc}
\hline № & $R_{2 X_{\varepsilon}}$ & $R_{3 X_{\varepsilon}}$ & $R_{4 X_{\varepsilon}}$ & $R_{5 X_{\varepsilon}}$ & $R_{6 X_{\varepsilon}}$ & $R_{7 X \varepsilon}$ & $R_{8 X_{\varepsilon}}$ & $R_{9 X_{\varepsilon}}$ & $\begin{array}{c}\text { Number and location of the area of } \\
\text { expected earthquake }\end{array}$ \\
\hline 13 & 14 & 15 & 16 & 17 & 18 & 19 & 20 & 21 & 22 \\
\hline 1 & 50 & 100 & - & 140 & - & - & - & - & Georgia (Sak'art’velo) \\
2 & 150 & 160 & 250 & - & - & - & - & - & Georgia (Sak’art’velo) \\
3 & - & 40 & - & 80 & - & 80 & - & - & Caucasus Region, Russia \\
4 & - & - & - & 150 & 250 & - & - & - & Iran-Iraq Border \\
5 & - & 110 & - & 110 & - & - & 40 & - & Caspian Sea, Offshore Azerbaijan \\
6 & - & 100 & - & 120 & - & - & - & - & Turkmenistan \\
7 & 110 & - & - & - & 180 & - & - & - & Western Iran \\
8 & 130 & - & - & - & 260 & 230 & - & - & Azerbaijan \\
9 & 25 & 40 & - & 100 & - & - & - & 80 & Offshore Turkmenistan \\
10 & 20 & 120 & - & - & - & 25 & - & - & Azerbaijan \\
\hline
\end{tabular}

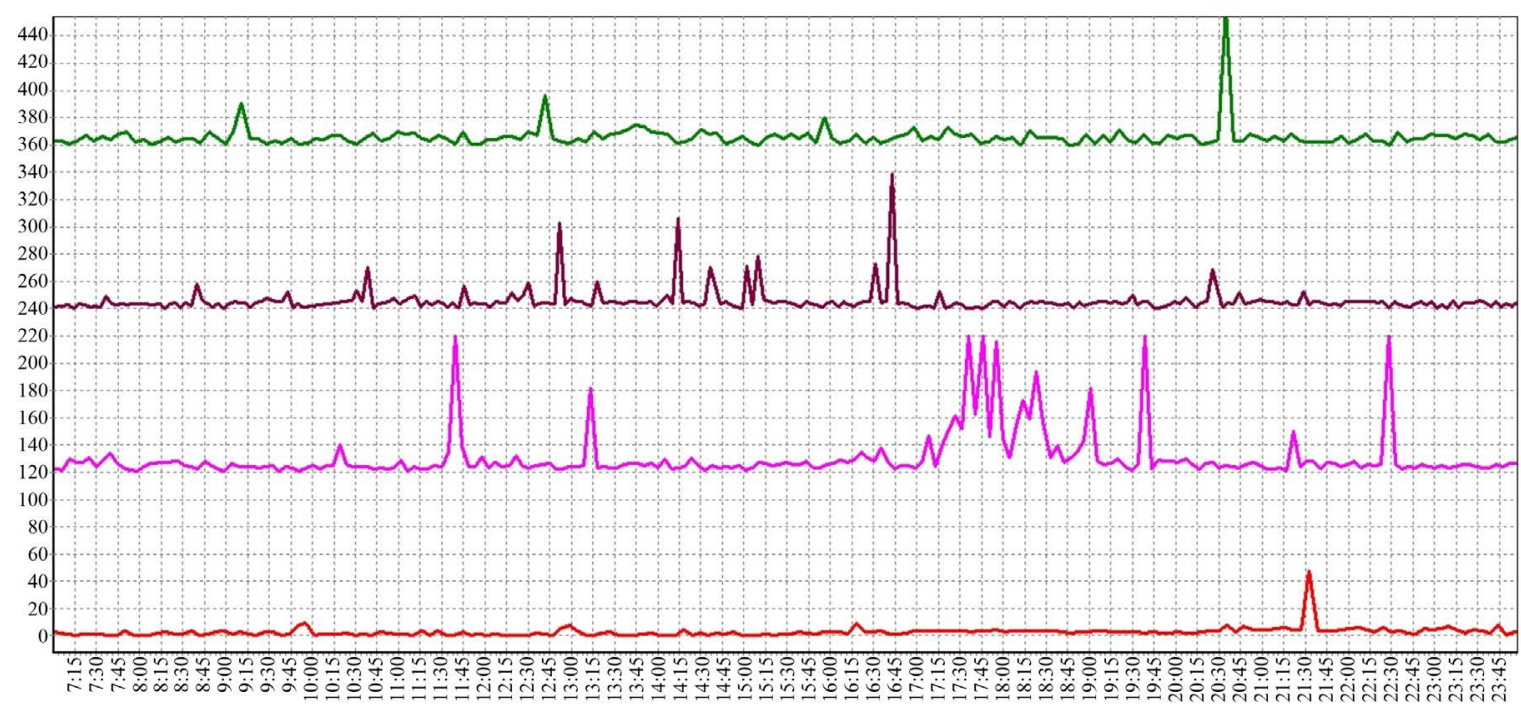

Figure 3. VII—Siazan, Naftalan, Shirvan, Qum Island 2013-05-27 Georgia (Sak'art'velo).

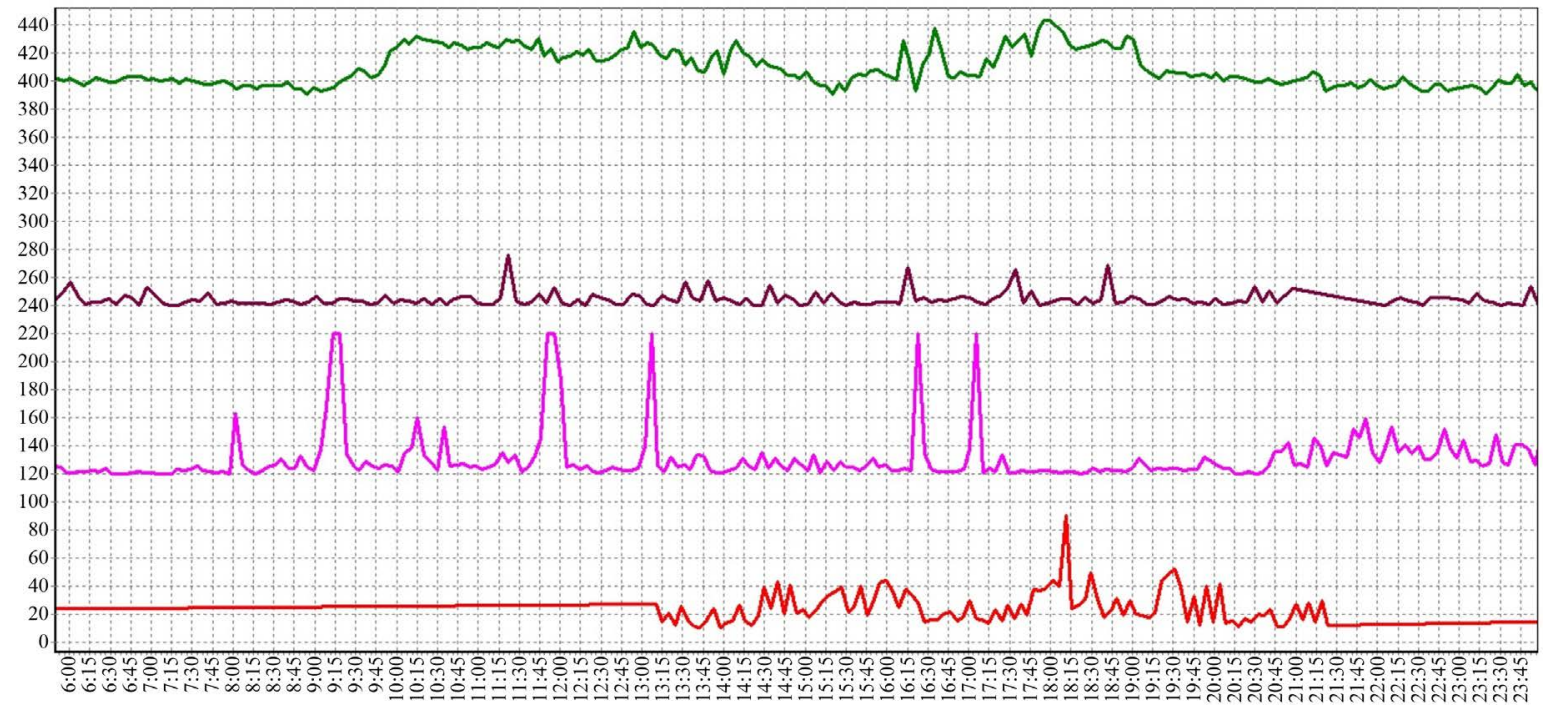

Figure 4. VII—Qazakh, Siazan, Qum Island, Neftchala 2013-09-16 Russia. 


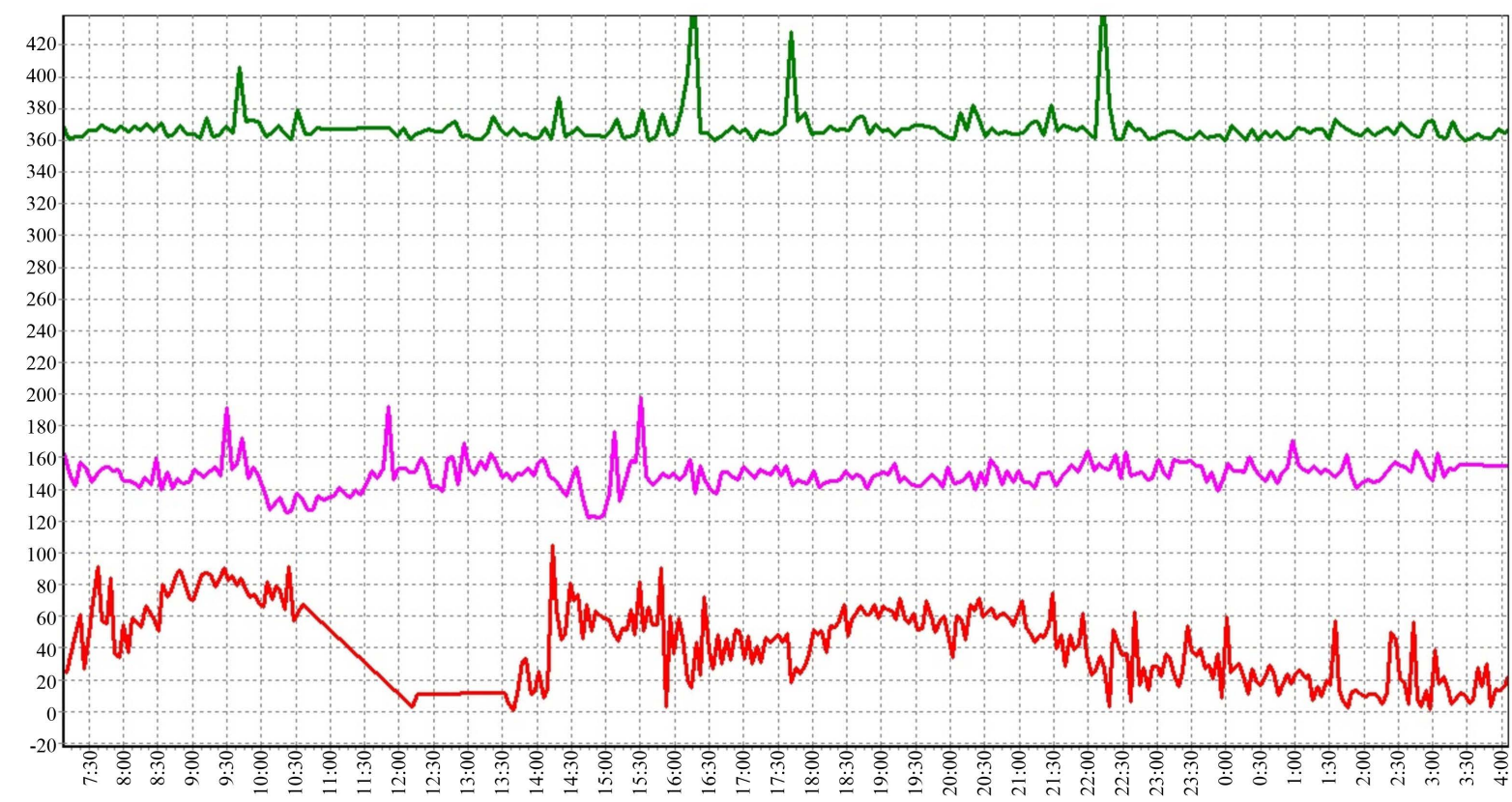

Figure 5. X-Qum Island, Neftchala, Nakhchivan 2013-11-21 Iran-Iraq border.

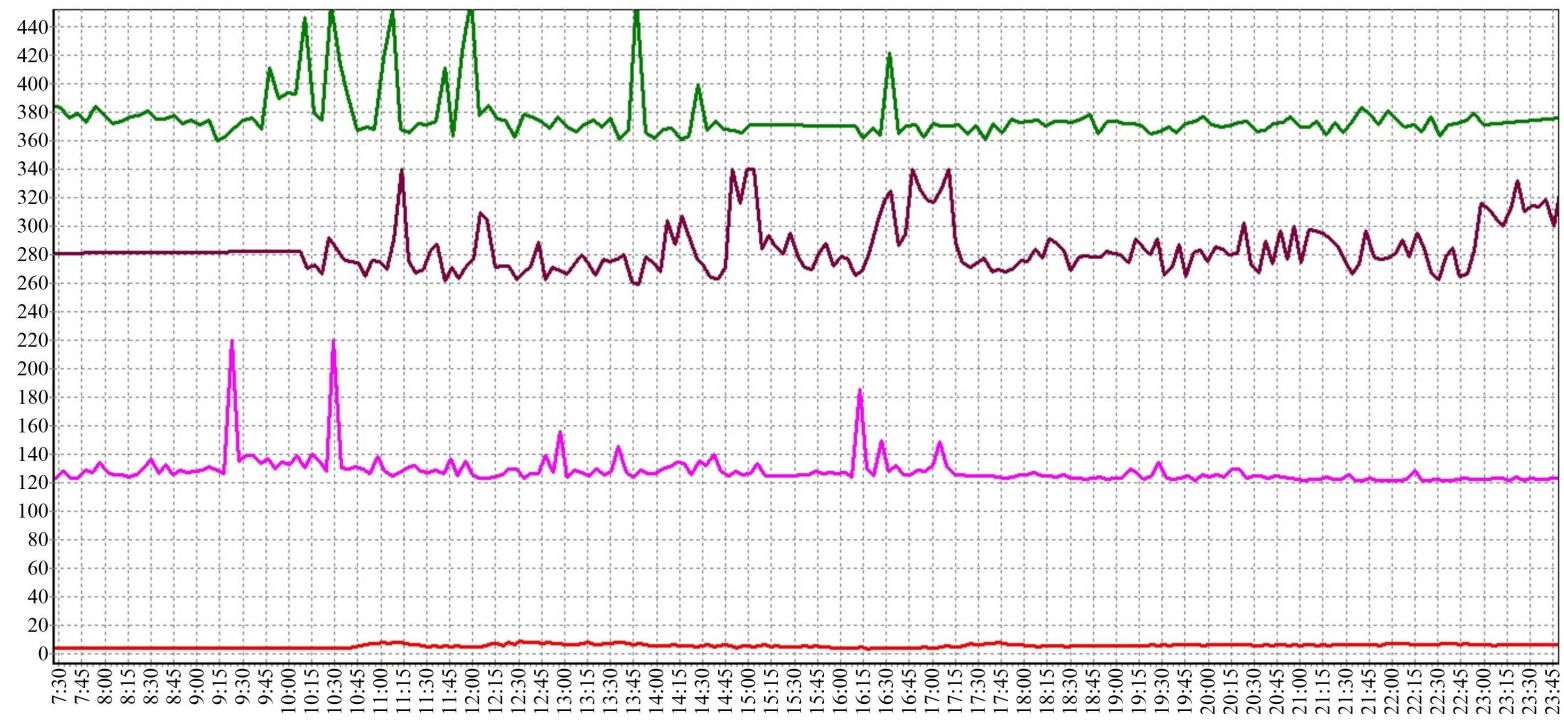

Figure 6. III-Siazan, Neftchala, Qum Island, Turkmen01 2014-01-09 Caspian Sea, Offshore Azerbaijan.

that preceded those earthquakes. The data in the first column in Table 1 are taken from the website of the Euro-Mediterranean Seismological Centre (EMSC) (http://www.emsc-csem.org/\#2).

The time of the earthquakes in Table 1 is given in UTC as provided by the EMSC website. The charts show the local time (Baku time), which is UTC+4 in the winter and UTC+5 in the summertime.

Column 22 of Table 1 provides information on the locations of the identified areas of expected earthquakes. To demonstrate the validity of those results, each row of the table is accompanied by relevant charts (Figures 2-11) recorded by the RNM ASP stations during the origin of the respective ASPs.

Sign "*” in Table 1 means that the station gave a weak reaction to the origin of the ASP of the expected earthquake. Sign "-” means that the value of the registered value of $R_{X \varepsilon}(\mu)$ is lower than the threshold level.

The first row of the table shows the results of the identification of the area of the earthquake that occurred in Georgia on 2013.03.26. It follows from Figure 2 that its beginning was indicated by the RNM ASP stations in 


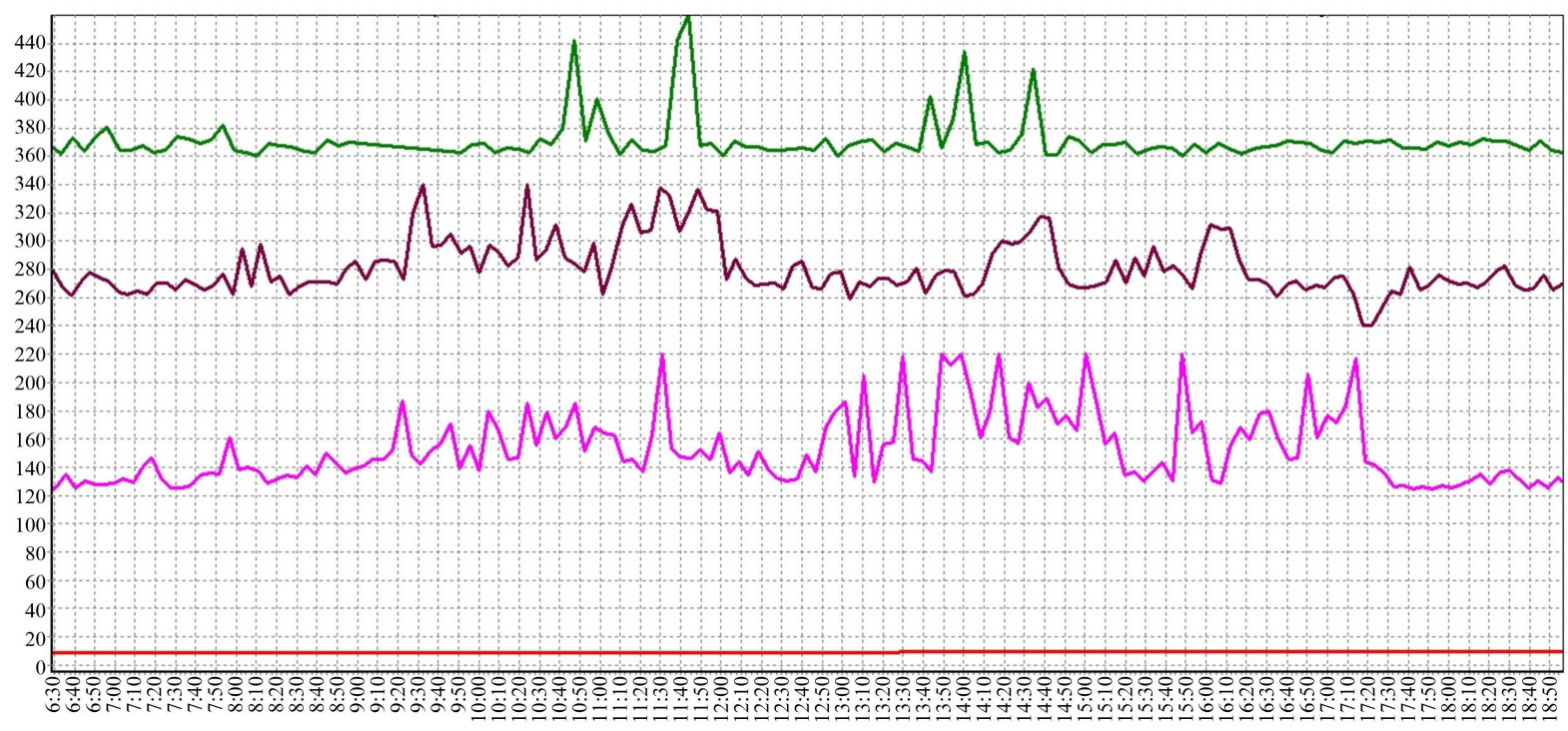

Figure 7. I-Siazan, Neftchala, Qum Island, Turkmen01 2014-01-13 Turkmenistan.

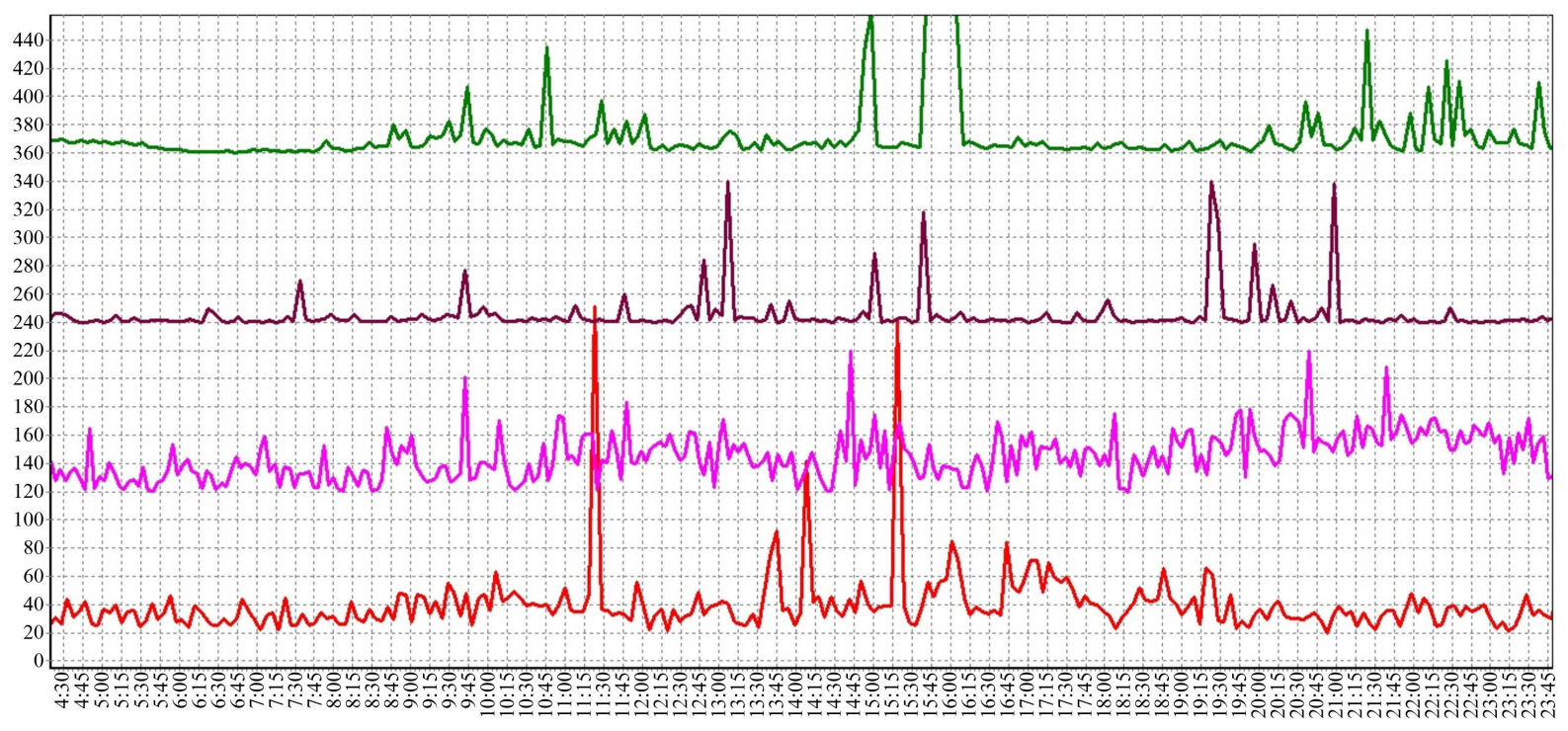

Figure 8. IX—Qum Island, Shirvan, Nakhchivan, Neftchala 2014-01-28 western Iran.

the following order: Siazan-04:15; Qum Island-04:30; Shirvan-06:50; Neftchala-08:30. Even though the Naftalan station was not operating at the time, the system identified that such an indication corresponded to area VII. The indication was 8 - 10 hours in advance of the earthquake.

Row 2 of the table gives the results of the identification of the area of the earthquake that occurred in Georgia on 2013.05.27, 2013.05.28. According to the chart, the RNM ASP stations Siazan, Naftalan, Shirvan and Qum Island registered the ASP origin more than 20 hours before the earthquake, despite the malfunction of the Naftalan station. It is clear from the charts that the northern (Siazan) and north-western (Qum Island) stations detected an anomaly earlier than the rest of the stations. The beginning of the anomalous processes was indicated by the RNM ASP stations in the following order: Naftalan-07:30; Siazan-09:10; Shirvan-09:45; Qum Island11:40 (Figure 3). Thus, the earthquake area was identified by the system by approximately 18:00 Baku time, which is almost 10 - 11 hours earlier than the time of registration by the ground stations.

Rows 3 of the table show the results of the identification of the area of the earthquakes that occurred in South Russia on2013.09.16. 


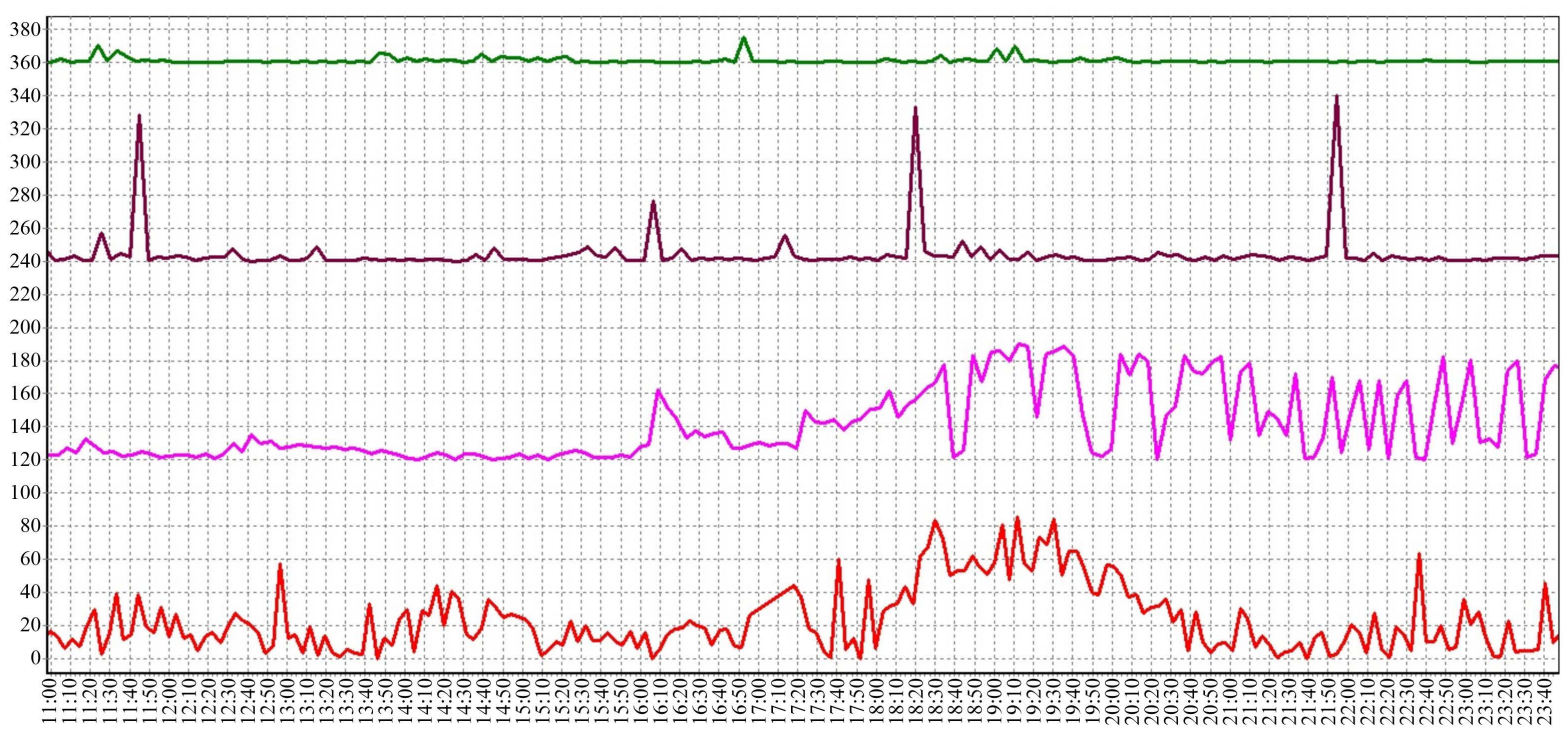

Figure 9. IV—Qum Island, Shirvan, Qazakh, Nakhchivan 2014-02-09 Azerbaijan.

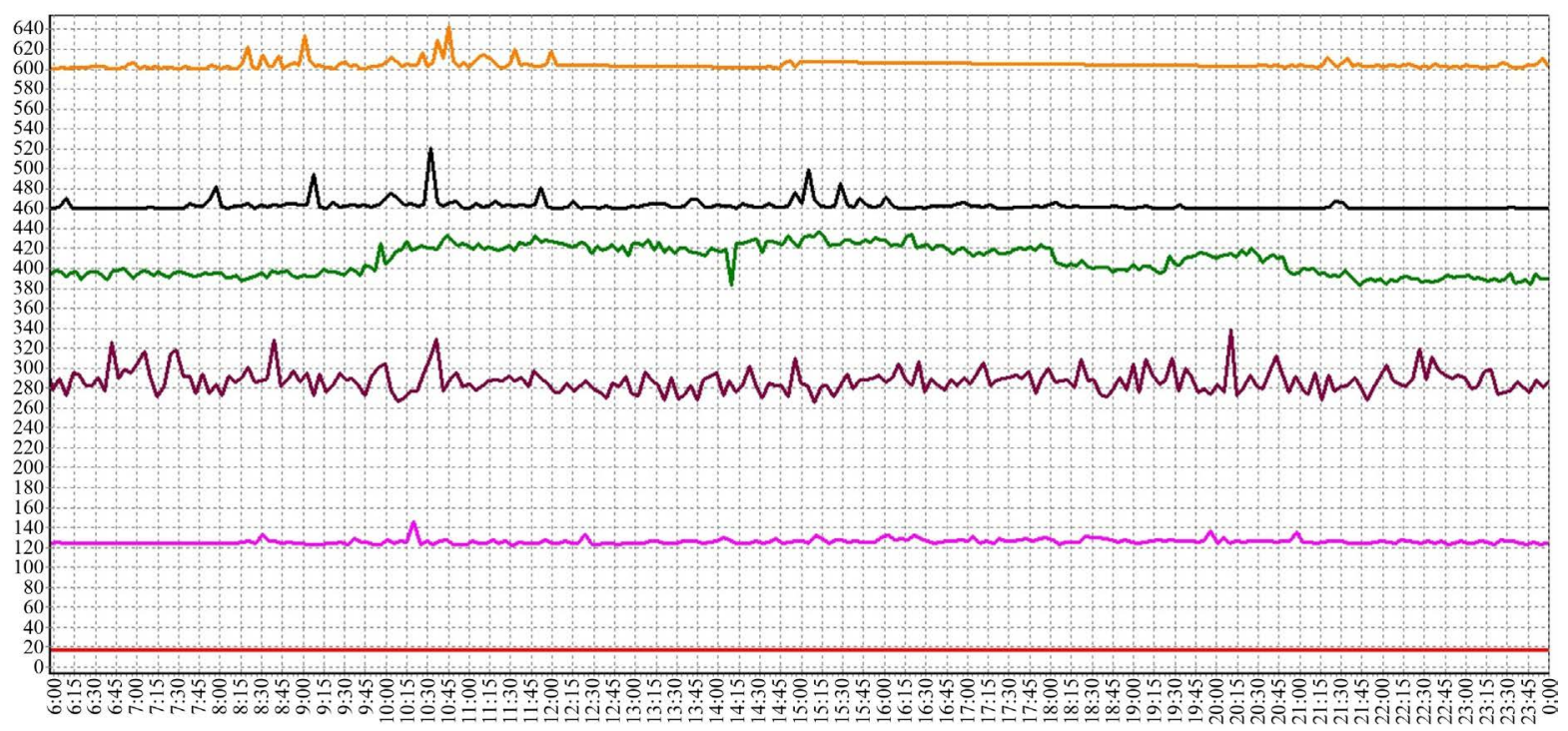

Figure 10. I—Siazan, Qum Island, Cybernetic, Neftchala, Shirvan, Turkmen01 2014-06-06 Caspian Sea, Offshore Turkmenistan.

According to the charts of the third and fourth earthquakes (Figure 4), the ASP originated in the south-east of the Caucasus region and registered in the following order: Siazan—05:30, Qum Island—08:00, Qazakh—10:00, Neftchala-14:30. Based on this sequence of registration times, the system identified earthquake area VII, which corresponds to the north-east of Azerbaijan, where an earthquake actually occurred at 16:00/17:00 Baku time. The time of the area identification was approximately 15 hours in advance of the earthquake.

According to the chart in Figure 5, based on the combination of times of registration by the stations Nakhchivan-08:00; Qum Island—09:00; Neftchala—08:50, the system identified the area of the expected earthquake on the Iran-Iraq border 12 hours beforehand.

Figure 6 shows the results of the identification of the area of the earthquake that occurred on 2014-01-09, at about 12:00, in the Caspian Sea, Offshore Azerbaijan, and was registered by the stations Turkmen01—09:15, Qum Island—09:25, Siazan—09:45, Neftchala—11:15, 16 hours in advance of the earthquake.

Row 6 of the table shows that the system identified the area of the expected earthquake in Turkmenistan. According to the chart in Figure 7, based on its sequence of registrations by the stations Neftchala—09:30, 


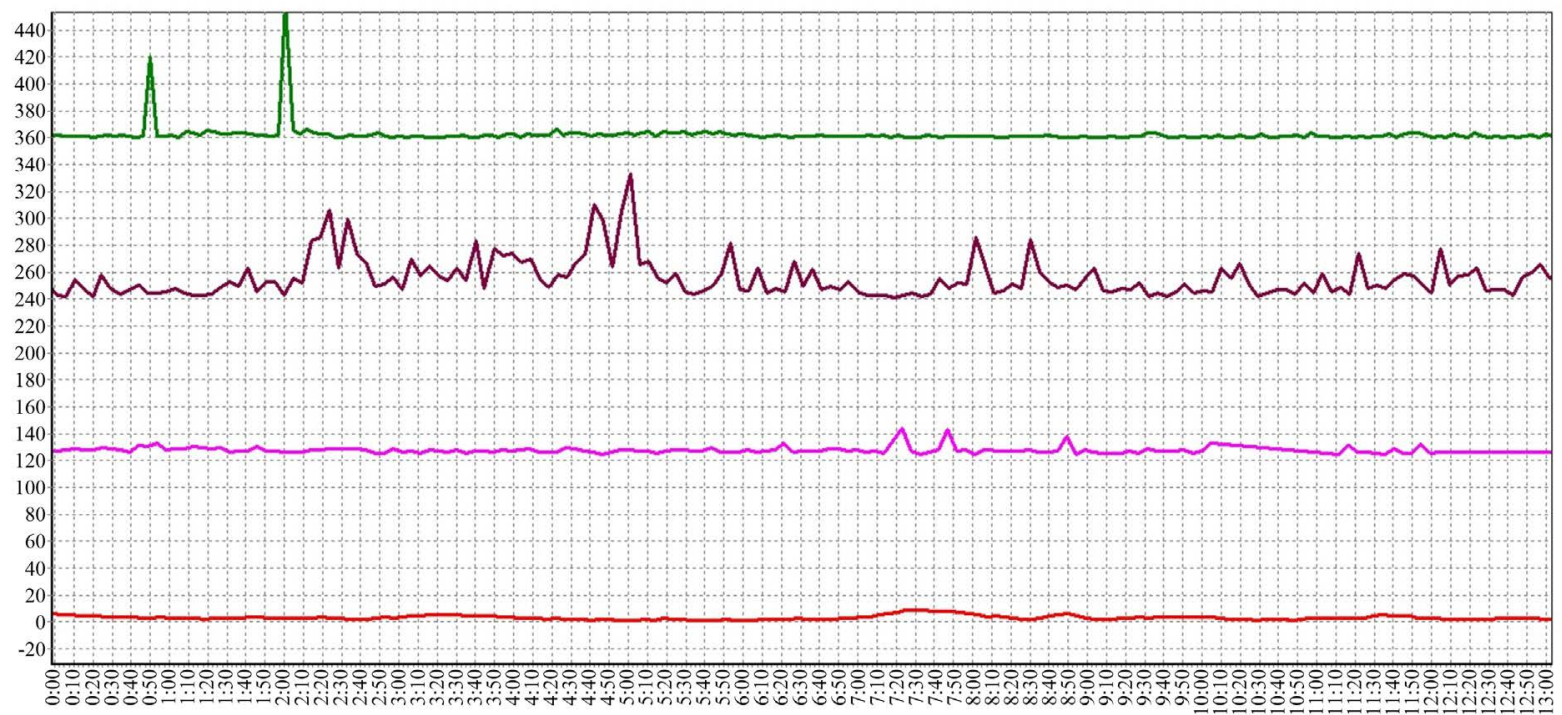

Figure 11. Siazan, Qum Island, Shirvan, Qazakh 2014-06-29 Azerbaijan.

Siazan-10:45, Qum Island-11:30, the system demonstrated that the location of the expected earthquake was in Turkmenistan, i.e. in area I east of Azerbaijan. The area of the expected earthquake was identified more than 24 hours before the earthquake was registered.

Row 7 of Table 1 shows the results of the identification of the area of the earthquake that occurred in Western Iran. According to Figure 8, the sequence of registrations by the stations Qum Island-09:45, Shirvan—07:30, Nakhchivan - 04:50 and Neftchala_-11:20, allowed the system to identify the location of the earthquake in area IX-Western Iran.

Row 8 of Table 1 shows the results of the identification of the area of the earthquake that occurred in Azerbaijan. According to the charts in Figure 9, the stations registered the corresponding ASP in the following order: Qum Island-17:45, Shirvan-12:45, Qazakh-19:00 and Nakhchivan-18:30, which allowed the system to identify the number (IV) of the area of the expected earthquake with a lead time of 19 hours.

Row 9 of Table 1 shows the results of identification of the area of the earthquake that occurred in Offshore Turkmenistan. According to the charts in Figure 10, this event was registered by the stations Neftchala—06:45, Qum Island-07:55, Siazan—08:15, Cybernetic-09:55, Shirvan-10:20.

Row 10 of Table 1 contains the information on the identification of the location of the expected earthquake that occurred in area I in Azerbaijan. It follows from Figure 11 that the anomaly was indicated by the stations in the following order: Siazan-00:50, Qum Island-02:15, Shirvan-07:20, Qazakh-07:30, which allowed the system to identify the location of the area of the expected earthquake (Azerbaijan).

\section{Conclusions}

1) The intelligent system based on the network of the RNM ASP stations can be used as a tool for identifying the location of the area of an expected earthquake. The seismologist is supplied with the information containing the direction and the number of the area of the expected earthquake, current combinations of the ASP, and amount, list, date and magnitude of similar combinations registered in the given area during previous earthquakes. This information will allow the seismologist to evaluate the degree of authenticity of the obtained information on the location of the area of the expected earthquake. Having enough time before the earthquake occurs, the seismologist can involve other specialists in the decision-making process if there is any doubt, ruling out an accidental error.

2) The RNM ASP stations in the network of the proposed system are built on wells with different depths and, consequently, different characteristics. These characteristics are difficult to take into account in identifying the location of the area of an expected earthquake and in determining its magnitude.

Moreover, as the depth of a well increases, its cost increases sharply, too. This makes the building of the RNM ASP stations in the countries that have no suspended oil wells quite challenging. 
Considering the above-mentioned arguments, we recommend forming a network of stations built in 50 100-m deep water wells in the future, with hydrophones placed in the water column at a depth of $10-20 \mathrm{~m}$. To improve the authenticity and reliability of the identification of the location of the area of the expected earthquake, we found it appropriate to build a network consisting of a large number of stations (over 10 - 15) in wells of equal depth located at an equal distance from one another. Integration of the network of the RNM ASP stations of the countries in several seismically active regions via satellite communication can, in the long term, allow for increasing the authenticity and reliability of determining the coordinates of the location of an expected earthquake.

3) Our experiments have demonstrated that the reliability of the ASP monitoring results and the validity of the results of identification of the location of the area of an expected earthquake grow with the growth in earthquake strength. With the strength exceeding 5 points, the results of the identification of the earthquake location proved to be valid in almost all cases. The value of the estimate of the cross-correlation function $R_{X \varepsilon}(\mu)$ between the useful signal $X(i \Delta t)$ and the noise $\varepsilon(i \Delta t)$ decreases as the distance from the earthquake area grows. The value of the estimate of noise variance $D_{\varepsilon}$ increases as the distance from the area grows; the correlation $R_{X \varepsilon}(\mu) / R_{X \varepsilon \varepsilon}(\mu)$ decreases with distance and $D_{\varepsilon} / R_{X \varepsilon \varepsilon}$ increases. The propagation velocity of the seismic-acoustic noise in different types of medium, e.g. water, sand or clay, significantly varies. There is a correlation between the well depth and the radius of the ASP monitoring.

4) The experiments at the Qum Island station in the Caspian Sea have demonstrated that the monitoring range of that station is much wider than that of the stations located far from the Caspian Sea. Other stations in Siazan and Neftchala located near the Caspian Sea also have a wide monitoring range compared with other stations. Practically all seismic processes reaching the Caspian Sea are clearly registered by those stations. Therefore, in building networks of new stations, one should consider the fact that the sea is a "perfect conductor" for seismicacoustic noises emerging during ASP origin in the region.

5) The results obtained from the experimental data allow for the assumption that the lead time of the registration of the ASP origin by a seismic-acoustic RNM ASP station over standard seismic equipment is due to two factors.

First, seismic-acoustic waves that arise in the beginning of the ASP origin do not reach the Earth's surface due to the frequency characteristics of certain upper strata, which furthers their horizontal spread in deep strata as noise. Reaching the steel pipes of the well, seismic-acoustic waves transform into acoustic signals and go to the ground surface at the velocity of sound, where they are detected by a hydrophone. At the same time, low frequency seismic waves from seismic processes are perceived at the surface after a certain amount of time, when the earthquake is already in progress, and are registered by seismic receivers of standard ground equipment much later.

Second, the use of noise technologies by analysing seismic-acoustic noise allows one, with the emergence of correlation between the useful signal and the noise, to register the ASPs in the beginning of their origin. These two factors make it possible for RNM ASP stations to indicate the time of the beginning of the ASP origin much earlier than is done by stations of the seismic survey service.

6) Seismic-acoustic stations of ASP monitoring can also be used for monitoring the latent period of volcano formation well before the eruption. Their use will also allow the monitoring, on a regional basis, of the testing of minor and major nuclear bombs and other experiments related to the manufacture of military equipment.

\section{Acknowledgements}

The authors express their gratitude to the SOCAR for providing suspended oil wells, as well as all the assistance and support in the construction of RNM ASP stations on those wells. This study was financed partially in the course of implementation of the following projects, for which the authors are immensely grateful. SOCAR project "Development of a network of seismic-acoustic stations for robust noise monitoring of anomalous seismic processes in the South Caucasus and Caspian basin using suspended oil wells as seismic-acoustic channels". SCIENCE \& TECHNOLOGY CENTER IN UKRAINE project. "Development of the technology for determination of coordinates of anomalous seismic processes". The study has been discussed among researchers from many countries during conferences and amicable meetings, and the authors wish to thank them for their interest and support. The researchers who participated actively in those discussions are: Nikolay Filimonov, Aleksandr Sidorin, Konstantin Kislov, Valeriy Mitko, Marina Minina, Lyubov Ebert, Orxan Polat, Alamdar Bayrakdar, 
Mehmet Kuruoglu, Afandi Nasibov, Ali Pinar, Dogan Kalafat, Aleksandr Kandzera, Murat Chariyev, Guljamal Chariyeva, Ioannis Baskoutas, Branden Kristensen, Taimi Mulder, Lutfulla Hamidov.

\section{References}

[1] Kanamori, H. and Brodsky, E.E. (2004) The Physics of Earthquakes. Reports on Progress in Physics. Reports on Progress in Physics, 67, 1429-1496. http://dx.doi.org/10.1088/0034-4885/67/8/R03

[2] Ghahari, F., Jahankhah, H. and Ghannad, M.A. (2010) Study on Elastic Response of Structures to Near-Fault Ground Motions through Record Decomposition. Soil Dynamics and Earthquake Engineering, 30, 536-546. http://dx.doi.org/10.1016/j.soildyn.2010.01.009

[3] Aliev, T.A., Abbasov, A.M., Aliev, E.R. and Guluyev, G.A. (2007) Digital Technology and the System for Receiving and Analyzing the Information from Deep Earth Layers for Noise-Monitoring the Technical State of the SociallySignificant Objects. Automatic Control and Computer Sciences, 41, 59-67. http://dx.doi.org/10.3103/S0146411607020010

[4] Yalcinkaya, E., Tekebas, S. and Pinar, A. (2013) Analysis of Ambient Noise in Yalova, Turkey: Discrimination between Artificial and Natural Excitations. Journal of Seismology, 17, 1021-1039. http://dx.doi.org/10.1007/s10950-013-9370-7

[5] Fischer, T. and Bachura, M. (2014) Detection Capability of Seismic Network Based on Noise Analysis and Magnitude of Completeness. Journal of Seismology, 18, 137-150. http://dx.doi.org/10.1007/s10950-013-9407-y

[6] Kislov, K.V. and Gravirov, V.V. (2011) Earthquake Arrival Identification in a Record with Technogenic Noise. Seismic Instruments, 47, 66-79. http://dx.doi.org/10.3103/S0747923911010129

[7] Yee, E., Stewart, J.P. and Schoenberg, F.P. (2011) Characterization and Utilization of Noisy Displacement Signals from Simple Shear Device Using Linear and Kernel Regression Methods. Soil Dynamics and Earthquake Engineering, 31, 25-32. http://dx.doi.org/10.1016/j.soildyn.2010.07.011

[8] Aliev, T. (2007) Digital Noise Monitoring of Defect Origin. Springer, London, 223 p.

[9] Aliev, T.A., Guluyev, G.A., Pashayev, F.H. and Sadygov, A.B. (2012) Noise Monitoring Technology for Objects in Transition to the Emergency State. Mechanical Systems and Signal Processing, 27, 755-762. http://dx.doi.org/10.1016/j.ymssp.2011.09.005

[10] Moser, P. and Moaveni, B. (2013) Design and Deployment of a Continuous Monitoring System for the Dowling Hall Footbridge. Experimental Techniques Society for Experimental Mechanics, 37, 15-26.

[11] Aliev, T.A., Abbasov, A.M., Guluyev, G.A., Pashayev, F.H. and Sattarova, U.E. (2013) System of Robust Noise Monitoring of Anomalous Seismic Processes. Soil Dynamics and Earthquake Engineering, 53, 11-25. http://dx.doi.org/10.1016/j.soildyn.2012.12.013

[12] Aliev, T.A., Abbasov, A.M., Guluyev, G.A., Pashayev, F.H. and Sattarova, U.E. (2012) Technologies and Systems for Minimization of Damage from Destructive Earthquakes. In: Etirmishli, G., Ed., Seismoforecasting Researches Carried out in the Azerbaijan Territory, Nafta-Press, Baku, 449-464.

[13] Hashemi, M. and Alesheikh, A.A. (2011) A GIS-Based Earthquake Damage Assessment and Settlement Methodology. Soil Dynamics and Earthquake Engineering, 31, 1607-1617. http://dx.doi.org/10.1016/j.soildyn.2011.07.003

[14] Kanamori, H. (2005) Real-Time Seismology and Earthquake Damage Mitigation. Annual Review of Earth and Planetary Sciences, 33, 195-214. http://dx.doi.org/10.1146/annurev.earth.33.092203.122626

[15] Colak, O.H., Destici, T.C., Ozen, S., Arman, H. and Cerezci, O. (2006) Frequency-Energy Characteristics of Local Earthquakes Using Discrete Wavelet Transform (DWT). World Academy of Science, Engineering and Technology, 20, 38-41.

[16] Hutton, D.V. (2004) Fundamentals of Finite Element Analysis. The McGraw-Hill Companies, New York, 494 p.

[17] Lockwood, O.G. and Kanamori, H. (2006) Wavelet Analysis of the Seismograms of the 2004 Sumatra-Andaman Earthquake and Its Application to Tsunami Early Warning. Geochemistry Geophysics Geosystems, 7, 1-10. http://www.agu.org/journals/abs/2006/2006GC001272.shtml

[18] Descherevsky, A.V., Lukk, A.A., Sidorin, A.Y., Vstovsky, G.V. and Timashev, S.F. (2003) Flicker-Noise Spectroscopy in Earthquake Prediction Research. Natural Hazards and Earth System Sciences, 3, 159-164. http://dx.doi.org/10.5194/nhess-3-159-2003

[19] Shebalin, P., Keilis-Borok, P., Gabrielov, A., Zaliapin, I. and Turcotte, D. (2006) Short-Term Earthquake Prediction by Reverse Analysis of Lithosphere Dynamics. Tectonophysics, 413, 63-75. http://dx.doi.org/10.1016/j.tecto.2005.10.033

[20] Aliev, T.A., Alizadeh, T.A. and Abbasov, A.M. (2005) Method for Monitoring the Beginning of Anomalous Seismic Process. International Application No. PCT/AZ2005/000006, Pub. No. WO2006/130933, International Filling Date19 December 2005. 
[21] Aliev, T.A., Abbasov, A.M., Aliev, E.R. and Guluyev, G.A. (2006) Method for Monitoring and Forecasting Earthquakes. International Application No PCT/AZ2006/00000, Pub. No. WO2007/143799, International Filling Date-16 June 2006.

[22] Papagiannopoulos, G.A. and Beskos, D.E. (2006) On a Modal Damping Identification Model for Building Structures. Archive of Applied Mechanics, 76, 443-463. http://dx.doi.org/10.1007/s00419-006-0046-4

[23] Papagiannopoulos, G.A. and Beskos, D.E. (2009) On a Modal Damping Identification Model for Non-Classically Damped Structures Subjected to Earthquakes. Soil Dynamics and Earthquake Engineering, 29, 583-589. http://dx.doi.org/10.1016/j.soildyn.2008.10.005

[24] Zafarani, H., Noorzad, A., Ansari, A. and Bargi, K. (2009) Stochastic Modeling of Iranian Earthquakes and Estimation of Ground Motion for Future Earthquakes in Greater Tehran. Soil Dynamics and Earthquake Engineering, 29, $722-741$. http://dx.doi.org/10.1016/j.soildyn.2008.08.002

[25] Rydelek, P. and Pujol, J. (2004) Real-Time Seismic Warning with a Two-Station Subarray. Bulletin of the Seismological Society of America, 94, 1546-1550. http://dx.doi.org/10.1785/012003197

[26] Stankiewicz, J., Bindi, D., Oth, A. and Parolai, S. (2013) Designing Efficient Earthquake Early Warning Systems: Case Study of Almaty, Kazakhstan. Journal of Seismology, 17, 1125-1137. http://dx.doi.org/10.1007/s10950-013-9381-4

[27] Alcik, H., Ozel, O., Wu, Y.M., Ozel, N.M. and Erdik, M. (2011) An Alternative Approach for the Istanbul Earthquake Early Warning System. Soil Dynamics and Earthquake Engineering, 31, 181-187. http://dx.doi.org/10.1016/j.soildyn.2010.03.007

[28] Satriano, C., Wub, Y.-M., Zollo, A. and Kanamori, H. (2011) Earthquake Early Warning: Concepts, Methods and Physical Grounds. Soil Dynamics and Earthquake Engineering, 31, 106-118. http://dx.doi.org/10.1016/j.soildyn.2010.07.007

[29] Tsuboi, S., Saito, M. and Kikuchi, M. (2002) Real-Time Earthquake Warning by Using Broadband P Waveform. Geophysical Research Letters, 29, 2187-2191. http://dx.doi.org/10.1029/2002GL016101

[30] Aliev, T.A., Alizadeh, A.A., Etirmishli, G.D., Guluyev, G.A., Pashayev, F.G. and Rzaev, A.G. (2011) Intelligent Seismoacoustic System for Monitoring the Beginning of Anomalous Seismic Process. Seismic Instruments, 47, 15-23. http://dx.doi.org/10.3103/S0747923911010026

[31] Aliev, T.A., Abbasov, A.M., Mamedova, G.G., Guluyev, G.A. and Pashayev, F.G. (2013) Technologies for Noise Monitoring of Abnormal Seismic Processes. Seismic Instruments, 49, 64-80. http://dx.doi.org/10.3103/S0747923913010015 